\title{
Self-reported confidence and perceived training needs of surgical interns at a regional hospital in Ghana: a questionnaire survey
}

Mee Joo Kang ${ }^{1,2}$ and Reuben Kwesi Sakyi Ngissah ${ }^{2^{*}}$ (D)

\begin{abstract}
Background: Due to disparities in their regional distribution of the surgical specialists, those who have finished "housemanship," which is the equivalent of an internship, are serving as main surgical care providers in rural areas in Ghana. However, the quantitative volume of postgraduate surgical training experience and the level of selfreported confidence after formal training have not been investigated in detail in sub-Saharan Africa.

Methods: The quality-assessment data of the Department of surgery at a regional hospital in Ghana was obtained from the convenience samples of house officers (HOs) who had their surgical rotation before July 2019. A selfreported questionnaire with 5-point Likert-type scale and open-ended responses regarding the 35 topics listed as learning objectives by the Medical and Dental Council of Ghana were retrospectively reviewed to investigate the volume of surgical experience, self-reported confidence, and perceived training needs.
\end{abstract}

Results: Among 52 respondents, the median self-reported number of patients experienced for each condition was less than 11 cases. More than $40 \%$ of HOs reported that they had never experienced cases of liver tumor $(n=21$, $40.4 \%)$, portal hypertension ( $n=23,44.2 \%)$, or cancer chemotherapy/cancer therapy $(n=26,50.0 \%)$. The median self-confidence score was 3.69 (interquartile range, 3.04 4.08). More than $50 \%$ of HOs scored $\leq 2$ points on the selfconfidence scale of gastric cancer $(n=28,53.8 \%)$, colorectal cancer $(n=31,59.6 \%)$, liver tumors $(n=32,61.5 \%)$, and cancer chemotherapy/cancer therapy $(n=38,73.1 \%)$. The top 3 reasons for not feeling confident were the limited number of patients $(n=42,80.8 \%)$, resources and infrastructure $(n=21,40.4 \%)$, and amount of supervision $(n=18$, 34.6\%). Eighteen HOs (34.6\%) rated their confidence in their surgical skills as $\leq 2$ points. Of all respondents, $76.9 \%$ $(n=40)$ were satisfied with their surgical rotation and $84.6 \%(n=44)$ perceived the surgical rotation as relevant to their future work. Improved basic surgical skills training $(n=27,51.9 \%)$ and improved supervision $(n=18,34.6 \%)$ were suggested as a means to improve surgical rotation.

Conclusions: Surgical rotation during housemanship (internship) should be improved in terms of cancer treatment, surgical skills, and supervision to improve the quality of training, which is closely related to the quality of surgical care in rural areas.

Keywords: Surgery, Surgical education, Curriculum, Confidence, Internship, Developing countries

\footnotetext{
* Correspondence: rngissah@yahoo.com

2Department of Surgery, Greater Accra Regional Hospital, P.O. Box 473, Accra, Republic of Ghana

Full list of author information is available at the end of the article
}

(c) The Author(s). 2020 Open Access This article is licensed under a Creative Commons Attribution 4.0 International License, which permits use, sharing, adaptation, distribution and reproduction in any medium or format, as long as you give appropriate credit to the original author(s) and the source, provide a link to the Creative Commons licence, and indicate if changes were made. The images or other third party material in this article are included in the article's Creative Commons licence, unless indicated otherwise in a credit line to the material. If material is not included in the article's Creative Commons licence and your intended use is not permitted by statutory regulation or exceeds the permitted use, you will need to obtain permission directly from the copyright holder. To view a copy of this licence, visit http://creativecommons.org/licenses/by/4.0/. The Creative Commons Public Domain Dedication waiver (http://creativecommons.org/publicdomain/zero/1.0/) applies to the data made available in this article, unless otherwise stated in a credit line to the data. 


\section{Background}

Inadequate infrastructure, supplies, and human resources for essential surgical care have been observed in Low-andMiddle-Income Countries (LMICs) [1]. Regarding human resources, a severe shortage of surgical specialist workforce has been widely emphasized [2]. In the World Health Organization (WHO) African region, the density of surgeons, anesthesiologists, and obstetricians was 1.0 per 100,000 population [3], which is far behind the target of 20 to 40 per 100,000 population [4]. Inequitable regional distribution of doctors within the country has also been pointed out [5]. For example, in Ghana, although the overall doctor-to-population ratio is decreasing, $58.3 \%$ of non-specialist doctors and $68.0 \%$ of specialists are working in two major regions of the country, where $35.4 \%$ of the overall population resides [6].

Apart from short-term surgical training of nonspecialist physicians [7] or task-shifting to non-physician clinicians [8, 9], training more surgical specialists has been a main stem concerning the surgical workforce. To increase the specialist surgical workforce, postgraduate surgical training in Africa has been established by the West African College of Surgeons (WACS) [10], the Ghana College of Physicians and Surgeons (GCPS) [10], and the College of Surgeons of East, Central, and Southern Africa (COSECSA) [11]. In Ghana, although formal residency training is well-developed, a low number of physicians is entering surgical residency and only a few qualified surgeons are being trained every year. In addition, it is rare for surgical specialists to work in rural areas [12]. As a consequence, medical officers who have completed the period of housemanship are the main surgical care providers in Ghanaian district hospitals [13].

A recent systematic review reported that 19 of the 34 LMICs had an internship or housemanship program [14]. Although one must complete this mandatory period of training to earn a full medical license, the quality of training during this period has not been prioritized and there is little baseline data related to it. This period of training should be considered seriously because the rates of enrollment in residency programs are low in LMICs and the majority of doctors who work in rural areas are those who have just finished their housemanship or internship $[12,13]$. However, it has been reported that medical officers experienced few supervised cases during their formal training, although they were responsible for performing major surgical procedures at district hospitals $[12,13]$.

Therefore, improving the quality of the surgical education of house officers (HOs) during housemanship would be a realistic and effective approach to improve the quality of surgical care, especially in rural areas. In this study, the authors report the HOs' degree of experience and level of self-confidence in surgical conditions after surgical rotation to highlight the current status of HOs' surgical competency and provide baseline data to improve the quality of surgical training.

\section{Methods \\ Overview of housemanship in Ghana}

In Ghana, the two-year housemanship period consists of four six-month rotations between internal medicine, obstetrics and gynecology, pediatrics, and surgery, and takes place shortly after medical school graduation [15]. During housemanship, two of the four rotations are done at teaching hospitals or their equivalents, including regional hospitals [15]. Emphasizing the importance of surgical rotation, the Medical and Dental Council (MDC) of Ghana has provided 35 conditions or procedures that can be managed by HOs "to prepare the house officer for safe and independent practice either in the community or health facility" [16].

\section{Study site}

Located in the capital city Accra, the Greater Accra Regional Hospital (GARH) is one of the 10 regional hospitals in Ghana. The Department of surgery at GARH has 17 specialists (six general surgeons, four trauma and orthopedic surgeons, three urologists, two neurosurgeons, one pediatric surgeon, and one plastic and reconstructive surgeon). The annual volume of surgeries in the department is 1100 cases on average, $44 \%$ of cases being emergency operations. Among the specialties, the proportion of general surgery cases is the highest (43\%), followed by trauma and orthopedic surgery (20\%) and urology (13\%). The department accommodates an average of 24 surgical HOs each term.

\section{Data collection}

From July to August 2019, a quality assessment of the Department of Surgery was conducted with a convenience sample of HOs who had their surgical rotations before July 2019 at GARH. HOs voluntarily responded to the electronic evaluation form, which was anonymized and did not collect any personal identifiable information, such as name, age, gender, or personal contacts. The duration of the respondents' surgical rotations, number of cases experienced, self-confidence regarding the 35 topics listed as learning objectives by the Medical and Dental Council of Ghana, and level of satisfaction with the surgical rotation were rated on a 5-point Likert-type scale. The details of the evaluation form are listed in Table 1. Concerning level of satisfaction and relevance, four or five points were considered satisfactory and relevant.

\section{Data analysis}

The quality assessment results were retrospectively reviewed to evaluate the surgical competency of the 
Table 1 Details of the evaluation form

\begin{tabular}{|c|c|}
\hline Questions & Options and measures \\
\hline \multicolumn{2}{|l|}{ Demographics } \\
\hline \multirow[t]{3}{*}{ Which year of housemanship are you in? ${ }^{a}$} & 1st year \\
\hline & 2nd year \\
\hline & Finished housemanship \\
\hline \multirow[t]{3}{*}{ How many months have you had surgical rotation? ${ }^{a}$} & Less than 2 months \\
\hline & $3 \sim 4$ months \\
\hline & $5 \sim 6$ months \\
\hline In which hospital did you have your surgical rotation? ${ }^{\text {a }}$ & Open question \\
\hline \multicolumn{2}{|l|}{ MDC checklist ( 35 conditions or procedures) } \\
\hline \multirow{5}{*}{$\begin{array}{l}\text { How many cases have you experienced the following conditions/ } \\
\text { procedures? }^{a}\end{array}$} & Never \\
\hline & $1 \sim 5$ cases \\
\hline & $6 \sim 10$ cases \\
\hline & $11 \sim 20$ cases \\
\hline & More than 21 cases \\
\hline \multirow{2}{*}{$\begin{array}{l}\text { Is there any condition/procedure you think not appropriate for } \\
\text { housemanship? }^{\text {a }}\end{array}$} & Yes \\
\hline & No \\
\hline If yes, please name them and briefly explain the reason. & Open question \\
\hline $\begin{array}{l}\text { Is there any condition/procedure you want to add for the housemanship } \\
\text { curriculum? }\end{array}$ & Open question \\
\hline $\begin{array}{l}\text { In what extent do you feel confident in managing the following conditions/ } \\
\text { procedures if you are on your own? }{ }^{\text {a }}\end{array}$ & $\begin{array}{l}1 \text { (not very confident) } \sim 5 \text { (very confident) in 5-point Likert-type } \\
\text { scale }\end{array}$ \\
\hline \multirow{7}{*}{$\begin{array}{l}\text { For the conditions/procedures that you don't feel confident, please explain } \\
\text { the reason. }{ }^{a}\end{array}$} & Multiple selection for; \\
\hline & Limited number of patients \\
\hline & Limited supervision \\
\hline & Limited resources and infrastructure \\
\hline & Limited timeframe for surgical rotation \\
\hline & Not interested in surgical conditions \\
\hline & Other (free text) \\
\hline \multicolumn{2}{|l|}{ Level of satisfaction and suggestions } \\
\hline In overall, how satisfied were you with the surgical rotation? ${ }^{a}$ & 1 (not very satisfied) $\sim 5$ (very satisfied) in 5-point Likert-type scale \\
\hline $\begin{array}{l}\text { How relevant and helpful do you think the surgical rotation was for your } \\
\text { future work? }\end{array}$ & 1 (not very relevant) $\sim 5$ (very relevant) in 5-point Likert-type scale \\
\hline \multirow[t]{6}{*}{ What were your key lessons learned during surgical rotation? ${ }^{a}$} & $\begin{array}{l}1 \text { (not very confident) } \sim 5 \text { (very confident) in 5-point Likert-type } \\
\text { scale for the following subdomains; }\end{array}$ \\
\hline & Preoperative management \\
\hline & Postoperative management \\
\hline & Surgical skills \\
\hline & Knowledge of basic principles \\
\hline & Others \\
\hline $\begin{array}{l}\text { Please describe any suggestions to improve the quality of the surgical } \\
\text { housemanship training }\end{array}$ & Open question \\
\hline
\end{tabular}

HOs during or after completing their surgical rotations and improve the quality of surgical training. Statistical analysis was conducted with STATA Version 15.1 (Stata Corp, Texas, USA). The aggregated scores for the number of cases experienced and self-confidence were derived from Likert-type scale scores in all 35 subdomains. The summary measures were presented in median and interquartile ranges (IQR) because the 
aggregated scores did not follow normal distribution tested by Shapiro-Wilk W test and graphical inspection. The continuous variables were analyzed using the Wilcoxon rank-sum test and the nominal variables were analyzed using a chi-square test or Fisher's exact test and Spearman correlation test. The two-sided $p$ values $<0.05$ were considered statistically significant. A thematic analysis was performed to analyze the results of the openended questions on the evaluation forms.

\section{Reliability and validity of the evaluation form}

A reliability analysis was carried out on the questions, with 35 conditions and procedures rated in terms of the number of cases experienced and the respondents' selfconfidence regarding them. The internal consistency of the responses was evaluated with the Cronbach's alpha value in each domain, which revealed that the questionnaire had an acceptable level of reliability (alpha value 0.969 [number of cases experienced] and 0.980 [self-confidence ratings]). As a consequence, all 35 topics were included for further analysis.

Construct validity of the level of satisfaction was demonstrated by positive correlation with the self-confidence score (Spearman's correlation coefficient 0.392, $p=$ 0.001). Although competence and confidence do not have a linear correlation [17], it is important for the HOs to achieve some degree of preparedness at least before they are posted to district or sub-district level hospitals as independent doctors. It is widely known that multiple factors affect self-efficacy beliefs in surgery [18], and case volume or length of training has a controversial correlation $[17,19]$. However, the self-confidence of surgical trainees has been reported to have a positive correlation with level of satisfaction [20]. Therefore, the authors investigated the level of satisfaction as a measure of experience and self-confidence obtained during the surgical rotation.

\section{Results}

\section{Characteristics}

The overall response rate was $95.9 \%$ (71/74). Seven of the 71 respondents who had parts of their surgical rotation at other facilities (five at teaching hospitals, two at district-level hospitals) were excluded to investigate the authentic training status of a regional hospital. Fifty-two of the remaining 64 respondents who had completed 5 to 6 months of surgical rotation in GARH were included for final analysis. Each $\mathrm{HO}$ has a different order of rotations between the specialties. Seven (13.5\%) were in their first year of housemanship, $11(21.2 \%)$ were in their second year, and 34 (65.4\%) had already finished the period of housemanship.

\section{Self-reported score for the number of cases experienced} during surgical rotation

Although there is a risk of recall bias, the number of cases experienced was directly asked in the questionnaire because the majority of the HOs fill up their logbook at the end of the year with a higher risk of recall bias and inaccuracy. The median self-reported score for the number of cases experienced for each condition was 3.37 (IQR, $2.75 \sim 3.81$ ). The median scores reported for each of the 35 conditions or procedures and the proportion of the HOs who had experienced five or fewer cases of them are shown in Table 2. The proportion of reported case scores for each topic is presented in Fig. 1. Eleven conditions or procedures were experienced in five or fewer cases in more than $50 \%$ of the HOs (shock, acute renal failure, chest injuries, peripheral vascular disease, typhoid, hand infections, colorectal cancer, gastric cancer, portal hypertension, liver tumors, and cancer chemotherapy/cancer therapy). More than $40 \%$ of the HOs reported that they had never experienced a case of liver tumor $(n=21$, $40.4 \%)$, portal hypertension $(n=23,44.2 \%)$, or cancer chemotherapy/cancer therapy $(n=26,50.0 \%)$.

Liver tumors $(n=1)$ and portal hypertension $(n=1)$ were identified as items that could be removed from the checklist because of the limited number of cases. Surgical skills training with simulation or hands-on training in the operating theater $(n=1)$, splenectomy $(n=1)$, and cancer chemotherapy $(n=1)$ were identified as items that could be added to it.

\section{Self-reported confidence score}

The median self-reported confidence score was 3.69 (IQR, 3.04 4.08). The median confidence scores reported for each of the 35 conditions or procedures and the proportion of the HOs who rated their selfconfidence as 1 or 2 points are shown in Table 3 . The proportions of reported confidence scores for each item are presented in Fig. 2. Four conditions scored 1 or 2 points on the self-confidence scale among more than $50 \%$ of HOs (gastric cancer, colorectal cancer, liver tumors, and cancer chemotherapy/cancer therapy). The self-reported confidence score was positively correlated with the self-reported score for the number of cases experienced (Spearman's correlation coefficient 0.601, $p<$ 0.001 ). Those who rated their confidence scores at 4 or 5 had higher self-reported scores for the number of cases experienced (median 3.66, IQR $3.47 \sim 4.09$ [confidence score $\geq 4, n=17$ ] vs. median 3.09, IQR $2.66 \sim 3.60$ [confidence score $<4, n=35$ ]; $p=0.011$ ).

Among the 11 items that the HOs had experienced five or fewer times during their surgical rotations, shock and typhoid had a relatively high proportion of HOs who rated their confidence scores at 4 or 5 (73.1 and $55.8 \%$, respectively). Of the four items that elicited 
Table 2 Self-reported case scores and proportion of house officers who experienced $\leq 5$ cases for the 35 items

\begin{tabular}{|c|c|c|}
\hline Conditions or procedures & $\begin{array}{l}\text { Case score } \\
\text { (median, IQR) }\end{array}$ & $\begin{array}{l}\text { Experienced } \leq 5 \text { cases } \\
(n=52)\end{array}$ \\
\hline Fracture management & $5(3,5)$ & $6(11.5 \%)$ \\
\hline The injured patient & $5(3,5)$ & $5(9.6 \%)$ \\
\hline Pre and postoperative care & $5(3,5)$ & $8(15.4 \%)$ \\
\hline Inguinoscrotal hernia & $5(3.5,5)$ & $5(9.6 \%)$ \\
\hline Wounds & $5(3,5)$ & $7(13.5 \%)$ \\
\hline Appendicitis & $5(3,5)$ & $6(11.5 \%)$ \\
\hline Application of P.O.P. & $5(3,5)$ & $8(15.4 \%)$ \\
\hline Preparation for and test for fitness for surgery & $5(3,5)$ & $8(15.4 \%)$ \\
\hline Acute abdomen & $5(3,5)$ & $9(17.3 \%)$ \\
\hline Blood transfusion & $5(3,5)$ & $10(19.2 \%)$ \\
\hline Retention of urine, including BPH/prostate cancer and urethral stricture & $4(3,5)$ & $8(15.4 \%)$ \\
\hline Fluid and electrolyte therapy & $4.5(3,5)$ & $12(23.1 \%)$ \\
\hline Anemia & $4(3,5)$ & $11(21.2 \%)$ \\
\hline Head injuries & $4(3,5)$ & $10(19.2 \%)$ \\
\hline Diabetes and its complications & $4(3,5)$ & $12(23.1 \%)$ \\
\hline Intestinal obstruction & $4(3,5)$ & $12(23.1 \%)$ \\
\hline Hematuria & $3.5(3,4)$ & $12(23.1 \%)$ \\
\hline Peptic ulcer disease and complications & $3(2,4)$ & $16(30.8 \%)$ \\
\hline Breast cancer & $3(2,4)$ & $17(32.7 \%)$ \\
\hline Nutrition in surgery & $3(2,4)$ & $22(42.3 \%)$ \\
\hline Gastrointestinal bleeding & $3(2,4)$ & $22(42.3 \%)$ \\
\hline Surgical infections & $3(2,3)$ & $20(38.5 \%)$ \\
\hline Jaundice & $3(2,4)$ & $22(42.3 \%)$ \\
\hline Burns & $3(2,3)$ & $25(48.1 \%)$ \\
\hline Shock & $2(2,3)$ & $28(53.8 \%)$ \\
\hline Acute renal failure & $2(2,3)$ & $33(63.5 \%)$ \\
\hline Chest injuries & $2(2,3)$ & $31(59.6 \%)$ \\
\hline Peripheral vascular disease & $2(2,3)$ & $32(61.5 \%)$ \\
\hline Typhoid & $2(2,3)$ & $35(67.3 \%)$ \\
\hline Hand infections & $2(2,3)$ & $36(69.2 \%)$ \\
\hline Colorectal cancer & $2(2,2)$ & $41(78.8 \%)$ \\
\hline Gastric cancer & $2(2,2)$ & $41(78.8 \%)$ \\
\hline Portal hypertension & $2(1,2.5)$ & 39 (75.0\%) \\
\hline Liver tumors & $2(1,2)$ & $46(88.5 \%)$ \\
\hline Cancer chemotherapy/cancer therapy & $1.5(1,2)$ & $43(82.7 \%)$ \\
\hline
\end{tabular}

scores of 1 or 2 points in regard to self-confidence among more than $50 \%$ of HOs, more than $78 \%$ of HOs experienced five or fewer cases during surgical rotation (colorectal cancer $n=41,78.8 \%$; gastric cancer $n=41$, $778.8 \%$; cancer chemotherapy/cancer therapy $n=43$, $82.7 \%$; liver tumors $n=46,88.5 \%$ ). The reasons given for the lack of confidence towards these topics are listed in Table 4.

\section{Level of satisfaction and relevance to future work}

Of all respondents, $76.9 \%(n=40)$ were satisfied with their surgical rotation and $84.6 \%(n=44)$ perceived the surgical rotation as relevant to their future work. The respondents' level of satisfaction with the surgical rotation had a statistically significant correlation with the number of cases experienced, self-confidence, and perception of its relevance to their future work (Spearman's 


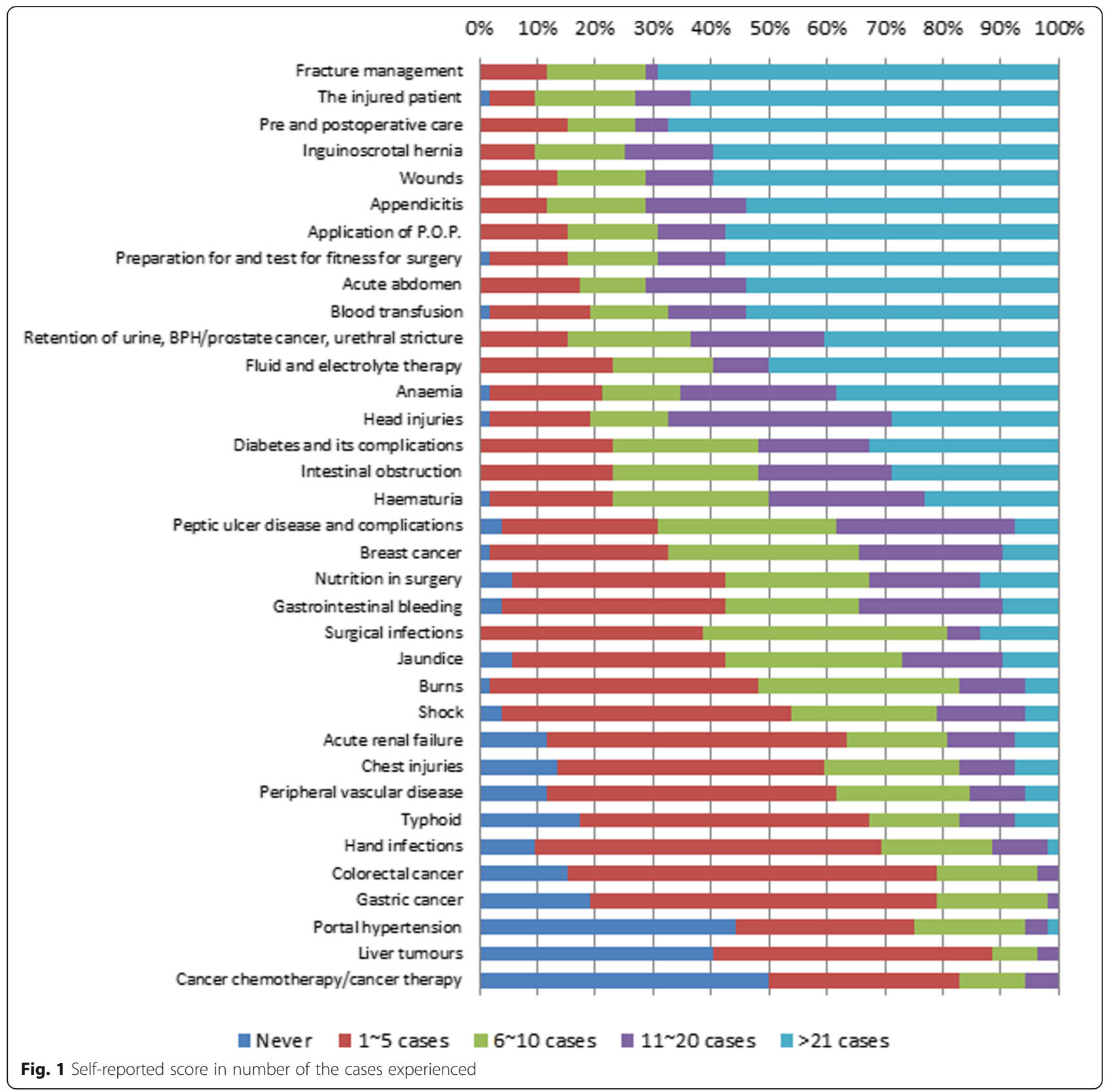

correlation coefficient $0.286[p=0.040], 0.290 \quad[p=$ $0.037]$, and $0.579[p<0.001]$, respectively).

\section{Key lessons learned during the surgical rotation}

The areas in which respondents felt most confidence after their surgical rotations were preoperative management, followed by postoperative management, knowledge of basic principles, and surgical skills (Fig. 3). In regard to surgical skills, $34.6 \%(n=18)$ of the respondents rated their confidence level as 1 or 2 points. Their level of confidence regarding surgical skills was not correlated with the mean self-reported number of cases experienced $(p=0.108)$. Those who had more confidence in their surgical skills perceived a higher level of satisfaction after the surgical rotation (Spearman's correlation coefficient $0.375, p=0.006$ ).

\section{Suggestions from the HOs}

Of the respondents, $36(69.2 \%)$ HOs responded to the open-ended portion of the survey with their suggestions for improving the quality of the surgical rotation (Table 5). Twenty-seven (51.9\%) suggested the introduction of basic surgical skills training, while 14 of them emphasized the need for hands-on training. A desire for more supervision in daily practice was expressed by 18 respondents $(34.6 \%)$. 
Table 3 Self-reported confidence scores and proportion of house officers who scored $\leq 2$ points for the 35 items

\begin{tabular}{|c|c|c|}
\hline Conditions or procedures & $\begin{array}{l}\text { Confidence score } \\
\text { (median, IQR) }\end{array}$ & Confidence score $\leq 2(n=52)$ \\
\hline Blood transfusion & $5(4.5,5)$ & $6(11.5 \%)$ \\
\hline Anemia & $5(4,5)$ & $6(11.5 \%)$ \\
\hline Pre and postoperative care & $5(4,5)$ & $6(11.5 \%)$ \\
\hline Wounds & $5(3,5)$ & $6(11.5 \%)$ \\
\hline Application of P.O.P. & $4(3.5,5)$ & $6(11.5 \%)$ \\
\hline Surgical infections & $4(3,5)$ & $7(13.5 \%)$ \\
\hline Preparation for and test for fitness for surgery & $5(3,5)$ & $9(17.3 \%)$ \\
\hline Shock & $4(3,5)$ & $6(11.5 \%)$ \\
\hline Fluid and electrolyte therapy & $4(3,5)$ & $7(13.5 \%)$ \\
\hline Fracture management & $4(3,5)$ & $6(11.5 \%)$ \\
\hline The injured patient & $4(3,5)$ & $7(13.5 \%)$ \\
\hline Appendicitis & $4(3,5)$ & $9(17.3 \%)$ \\
\hline Acute abdomen & $4(3,5)$ & $9(17.3 \%)$ \\
\hline Retention of urine, including $\mathrm{BPH} /$ prostate cancer and urethral stricture & $4(3,5)$ & $11(21.2 \%)$ \\
\hline Intestinal obstruction & $4(3,5)$ & $9(17.3 \%)$ \\
\hline Inguinoscrotal hernia & $4(3,5)$ & $10(19.2 \%)$ \\
\hline Diabetes and its complications & $4(3,5)$ & $7(13.5 \%)$ \\
\hline Peptic ulcer disease and complications & $4(3,5)$ & $9(17.3 \%)$ \\
\hline Gastrointestinal bleeding & $3(3,5)$ & $12(23.1 \%)$ \\
\hline Hematuria & $4(3,4)$ & $11(21.2 \%)$ \\
\hline Head injuries & $4(2,4.5)$ & $14(26.9 \%)$ \\
\hline Typhoid & $4(2,4.5)$ & $15(28.8 \%)$ \\
\hline Jaundice & $3(3,4)$ & $11(21.2 \%)$ \\
\hline Acute renal failure & $3(3,4.5)$ & $12(23.1 \%)$ \\
\hline Nutrition in surgery & $3(2,4)$ & $14(26.9 \%)$ \\
\hline Burns & $3(2,4)$ & $14(26.9 \%)$ \\
\hline Breast cancer & $3(2,4)$ & $20(38.5 \%)$ \\
\hline Chest injuries & $3(2,4)$ & $20(38.5 \%)$ \\
\hline Peripheral vascular disease & $3(2,4)$ & $22(42.3 \%)$ \\
\hline Hand infections & $3(2,4)$ & $23(44.2 \%)$ \\
\hline Portal hypertension & $2.5(1,4)$ & $26(50.0 \%)$ \\
\hline Gastric cancer & $2(2,3)$ & $28(53.8 \%)$ \\
\hline Colorectal cancer & $2(2,3)$ & $31(59.6 \%)$ \\
\hline Liver tumors & $2(1,3)$ & $32(61.5 \%)$ \\
\hline Cancer chemotherapy/cancer therapy & $2(1,3)$ & $38(73.1 \%)$ \\
\hline
\end{tabular}

\section{Discussion}

This study revealed that the HOs who had undergone training at the biggest regional hospital in Ghana experienced an average of six to 10 cases of each surgical condition or procedure during their 6-month rotations. The HOs had experienced more than six cases of benign conditions, including inguinoscrotal hernia, injury, appendicitis, acute abdomen, fracture management, intestinal obstruction, and peptic ulcer disease, with an average self-confidence score greater than 3.5. However, over $75 \%$ of the HOs had experienced five or fewer cases of cancer-related conditions (gastric cancer, colorectal cancer, liver tumors, and cancer chemotherapy/cancer therapy), with a self-confidence score lower than 2.5. As shown in the data, one of the main reasons for lack of confidence in treating the conditions was the limited number of patients with such conditions that the respondents had encountered. However, the learning 


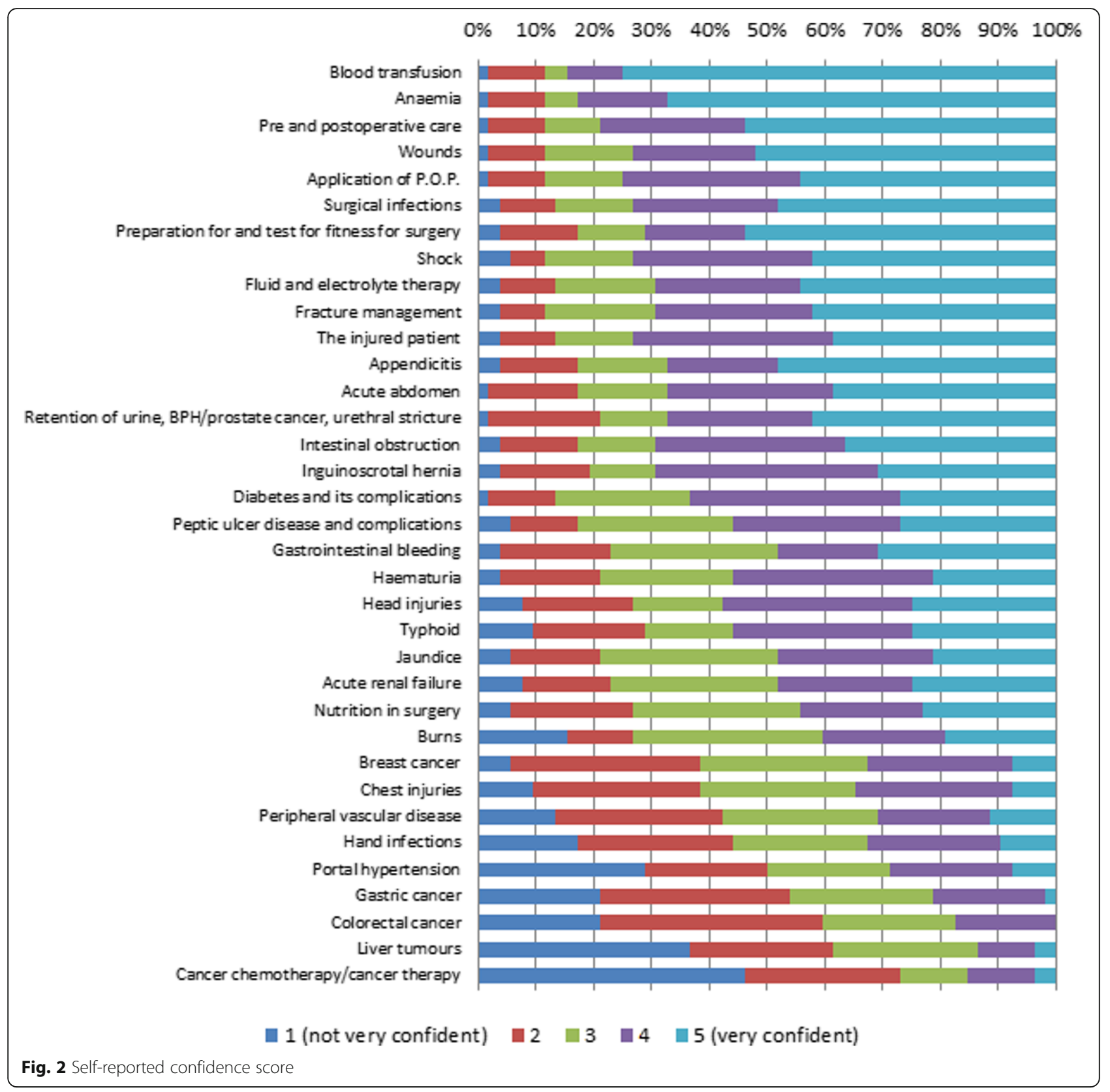

Table 4 Reasons for not feeling confident about the surgical conditions or procedures (multiple responses)

\begin{tabular}{ll}
\hline Theme & $\mathbf{N = 5 2 ~ ( \% )}$ \\
\hline Limited number of patients & $42(80.8 \%)$ \\
Limited resources and infrastructure & $21(40.4 \%)$ \\
Limited supervision & $18(34.6 \%)$ \\
Limited timeframe for surgical rotation & $7(13.5 \%)$ \\
Not interested in surgical conditions & $2(3.8 \%)$ \\
\hline
\end{tabular}

objectives suggested by MDC are in accordance with cancer prevalence in the surgical field, which showed that breast cancer had the highest prevalence in Ghana, followed by liver, colorectal, and gastric cancer (71.3, $8.2,7.9$, and 3.8 cases per 100,000 population, respectively) [21]. The incidence of cancer in Africa is increasing rapidly because of changes in demographics and lifestyle as well as the urbanization of the population [22]. Due to the high prevalence of breast cancer, the HOs had experienced more than six cases of it, with a self-confidence score of 3 . However, the regional hospital had inadequate case volumes for cancer treatment because the majority of cancer patients are referred to 


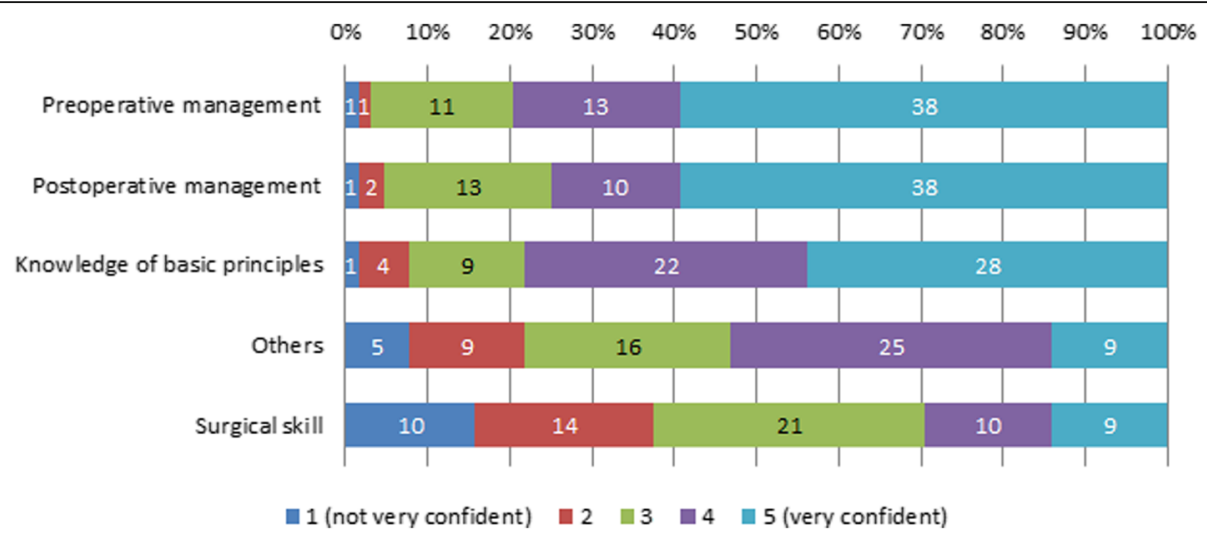

Fig. 3 Key lessons learned during the surgical rotation

teaching hospitals. Therefore, training for cancer treatment should not be overlooked, and solutions such as case-scenario training or rotation in oncology units at teaching hospitals should be considered to improve the quality of surgical training [23]. In addition, the current state of training at teaching hospitals should be investigated to decide where and how long the rotation should take place.

The level of satisfaction with surgical rotation was higher among those who reported a higher level of perceived relevance of the surgical rotation to their future work. The HOs who perceived that the surgical rotation was more relevant to their future work may have participated more actively during the training, which may have resulted in a higher level of self-confidence and satisfaction. This observation highlights the importance of motivation, which is critical for successful learning [24]. However, external motivation should also be provided for effective training. A review of postgraduate medical education in sub-Saharan Africa suggested that unstructured programs, high workload and fatigue, and limited incentives for supervisors were challenges to conducting effective training [23]. In this study, $34.6 \%$ of the HOs rated their self-confidence in surgical skills as 1 or 2 points, and $51.9 \%$ of the respondents suggested a need for basic surgical skills training with hands-on experiences, reflecting their unmet needs in surgical skills training [23]. To improve preparedness among surgical interns, techniques like "shadowing" current interns in

Table 5 Suggestions to improve quality of surgical rotation (multiple responses)

\begin{tabular}{ll}
\hline Theme & $\mathbf{N = 3 6 ( \% )}$ \\
\hline $\begin{array}{l}\text { Surgical skills, procedures, hands-on training } \\
\text { at the operating theater }\end{array}$ & $27(75.0 \%)$ \\
Supervision and teaching & $18(50.0 \%)$ \\
Rotation in various subspecialties & $1(2.8 \%)$ \\
\hline
\end{tabular}

the United Kingdom and participating in specialtyfocused surgical skills courses called "boot camps" in the United States have been utilized [25]. As a consequence, a weekly basic surgical skills training session that includes training in instrument handling, basic suturing techniques, and knot-tying commenced in 2019 at the Department of Surgery at GARH. However, the surgical procedures that the HOs must perform at district hospitals are beyond the scope of basic surgical skills [13]. Building on basic training, structured procedural skills training with exposure to real cases in the theater or emergency room is urgently needed.

On the other hand, $34.6 \%$ of respondents focused on the unsatisfactory supervision in daily practice. "Physically and mentally remote teachers" and "theoretical, inconsistent, and irrelevant teaching, such as grand rounds or didactic education sessions" have been reported as factors related to poor clinical practice [26]. However, unlike in developed countries, where the density of the specialist workforce is high, the massive workload caused by the paucity of specialists in LMICs makes it difficult for supervisors to maintain a strong passion for medical education. Supervisors' competing responsibilities, including clinical practice and administrative work, and limited acknowledgment of such educational activities by colleagues or institutions, impede the prioritization of education [27]. Therefore, rather than relying on moral responsibility, systemic support, including peer recognition, career development, and various incentives, should be considered.

In addition, the MDC checklist included all of the "must do" procedures (laparotomy, treatment of open and closed fracture, and wound debridement) and parts of the "should do" (hernia repair, gastroscopy, cholecystectomy, intracranial hematoma evacuation, and mastectomy) and "can do" (chest injuries, retention of urine, and hematuria) procedures in the Lancet Commission on Global Surgery's list in the field of general surgery 
[5]. However, some frequently performed "should do" procedures such as "superficial soft tissue tumor resection" or "thyroidectomy" were not listed in the MDC checklist, which requires reconsideration. Moreover, the majority of the current MDC checklist enlisted a broader concept of each condition, rather than specific surgical treatments or procedures, compared to the Lancet Commission on Global Surgery's list. As a consequence, "should do" procedures were theoretically covered in the MDC checklist, but it is difficult to confirm that the HOs were trained to perform gastroscopy, cholecystectomy, intracranial hematoma evacuation, or mastectomy. Understanding the comprehensive concept of each disease entity cannot be overemphasized for entry-level doctors. However, refining the learning objectives into more specific and measurable items focused on surgery would help the HOs and supervisors to set an attainable goal during the surgical rotation, which should be different from internal medicine. Therefore, careful revision of the MDC checklist with specified minimum requirements for teaching cases may foster the development of a standardized curriculum with better involvement of HOs and supervisors dedicating their time for surgical skills training and education sessions [24].

Despite its valuable contributions, this study has several limitations. First, the anonymized format of the evaluation form made it impossible to conduct in-depth qualitative studies, such as face-to-face or focus group interviews, to enrich the analysis. In addition, studies of supervisors must be conducted to ascertain the main challenges they face during the supervision and education of HOs. Second, discrepancies between self-rated confidence and actual competency should be considered [28]. Objective assessment tools for procedural skills should be adopted to evaluate the surgical HOs' competency in daily practice, and follow-up studies should incorporate this information. Lastly, the generalizability of this study's results is limited because the study was based on a single center located in the capital city of a West African country. Based on this study, further investigation of HOs at various levels of institutions and in multiple regions may facilitate the development of a better curriculum and training policy from a national perspective.

Despite these limitations, this study explored the respondents' degree of experience and self-confidence regarding surgical conditions after undergoing surgical rotation during housemanship, which is the only formal training that entry-level physicians receive before they are posted at district hospitals. Based on the data, further discussion, including approaches to increasing the motivation of HOs and improving the focus and quality of surgical rotation, is needed.

Abbreviation

HO: House officer

\section{Acknowledgements}

Not applicable.

\section{Authors' contributions}

RKSN and MJK made substantial contributions to the conception, design of the work, acquisition, analysis, and interpretation of data. MJK has drafted the work and RKSN substantively revised it. RKSN and MJK approved the submitted version and agreed both to be personally accountable for the author's own contributions and to ensure that questions related to the accuracy or integrity of any part of the work, even ones in which the author was not personally involved, are appropriately investigated, resolved, and the resolution documented in the literature.

\section{Authors' information}

The author MJK worked in Greater Accra Regional Hospital during the study period, analysis of the data and drafting. The manuscript was revised after the author MJK moved to National Cancer Center, Republic of Korea.

\section{Funding}

This research did not receive any specific grant from funding agencies in the public, commercial, or not-for-profit sectors.

\section{Availability of data and materials}

The datasets used and analyzed during the current study are available from the corresponding author on reasonable request.

\section{Ethics approval and consent to participate}

This study received institutional permission from the Greater Accra Regional Hospital, Accra, Republic of Ghana. The Ethics Review Committee of Ghana Health Service advised the authors to get an ethical clearance from the study site; hence this study received institutional permission with exemption of written consent from the Greater Accra Regional Hospital, Accra, Republic of Ghana.

\section{Consent for publication \\ Not applicable.}

\section{Competing interests}

The authors declare that they have no competing interests.

\section{Author details}

${ }^{1}$ Center for Liver and Pancreatobiliary Cancer, National Cancer Center, 323 Ilsan-ro, Ilsandong-gu, Goyang-si, Gyeonggi-do 10408, Republic of Korea. ${ }^{2}$ Department of Surgery, Greater Accra Regional Hospital, P.O. Box 473, Accra, Republic of Ghana.

Received: 14 April 2020 Accepted: 20 October 2020

Published online: 27 October 2020

\section{References}

1. Kushner AL, Cherian MN, Noel L, Spiegel DA, Groth S, Etienne C. Addressing the millennium development goals from a surgical perspective: essential surgery and anesthesia in 8 low- and middle-income countries. Arch Surg. 2010;145(2):154-9.

2. Hoyler M, Finlayson SR, McClain CD, Meara JG, Hagander L. Shortage of doctors, shortage of data: a review of the global surgery, obstetrics, and anesthesia workforce literature. World J Surg. 2014;38(2):269-80.

3. Holmer H, Lantz A, Kunjumen T, Finlayson S, Hoyler M, Siyam A, et al. Global distribution of surgeons, anaesthesiologists, and obstetricians. Lancet Glob Health. 2015;3(Suppl 2):S9-11.

4. Holmer H, Shrime MG, Riesel JN, Meara JG, Hagander L. Towards closing the gap of the global surgeon, anaesthesiologist, and obstetrician workforce: thresholds and projections towards 2030. Lancet. 2015;385(Suppl 2):S40.

5. Meara JG, Leather AJM, Hagander L, Alkire BC, Alonso N, Ameh EA, et al. Global surgery 2030: evidence and solutions for achieving health, welfare, and economic development. Lancet. 2015;386(9993):569-624.

6. Ghana Health Service. The health sector in Ghana: facts and figures. Accra: Ghana Health Service; 2018.

7. Chu K, Rosseel P, Gielis P, Ford N. Surgical task shifting in sub-Saharan Africa. PLoS Med. 2009;6(5):e1000078. 
8. Mullan F, Frehywot S. Non-physician clinicians in 47 sub-Saharan African countries. Lancet. 2007;370(9605):2158-63.

9. Pereira C, Cumbi A, Malalane R, Vaz F, McCord C, Bacci A, et al. Meeting the need for emergency obstetric care in Mozambique: work performance and histories of medical doctors and assistant medical officers trained for surgery. BJOG. 2007;114(12):1530-3.

10. Bode CO, Nwawolo CC, Giwa-Osagie OF. Surgical education at the west African College of Surgeons. World J Surg. 2008;32(10):2162-6.

11. Kakande I, Mkandawire N, Thompson MIW. A review of surgical capacity and surgical education programmes in the COSECSA region. East Cent Afr J Surg. 2011;16(3):6-34.

12. Choo S, Perry H, Hesse AA, Abantanga F, Sory E, Osen H, et al. Surgical training and experience of medical officers in Ghana's district hospitals. Acad Med. 2011;86(4):529-33.

13. Abdullah F, Choo S, Hesse AA, Abantanga F, Sory E, Osen H, et al. Assessment of surgical and obstetrical care at 10 district hospitals in Ghana using on-site interviews. J Surg Res. 2011;171(2):461-6.

14. Rickard J. Systematic review of postgraduate surgical education in low- and middle-income countries. World J Surg. 2016;40(6):1324-35.

15. Medical and Dental Council. Guidlines for housemanship in Ghana. Accra: Medical and Dental Council of Ghana; 2015.

16. Medical and Dental Council. Log book for housemanship training. Accra: Medical and Dental Council of Ghana; 2019

17. Elfenbein DM. Confidence crisis among general surgery residents: a systematic review and qualitative discourse analysis. JAMA Surg. 2016; 151(12):1166-75.

18. Geoffrion R, Koenig NA, Sanaee MS, Lee T, Todd NJ. Optimizing resident operative self-confidence through competency-based surgical education modules: are we there yet? Int Urogynecol J. 2019;30(3):423-8.

19. Leopold SS, Morgan HD, Kadel NJ, Gardner GC, Schaad DC, Wolf FM. Impact of educational intervention on confidence and competence in the performance of a simple surgical task. J Bone Joint Surg Am. 2005;87(5): 1031-7.

20. Geoffrion $R$, Lee $T$, Singer J. Validating a self-confidence scale for surgical trainees. J Obstet Gynaecol Can. 2013;35(4):355-61.

21. Global cancer observatory. International Agency for Research on Cancer, Lyon. 2018. https://gco.iarc.fr. Accessed 21 Oct 2019.

22. Bray F. Transitions in human development and the global cancer burden. In: World cancer report 2014. International Agency for Research on Cancer. 2014. http://publications.iarc.fr/396. Accessed 21 Oct 2019.

23. Talib Z, Narayan L, Harrod T. Postgraduate medical education in subSaharan Africa: a scoping review spanning 26 years and lessons learned. J Grad Med Educ. 2019;11(4 Suppl):34-46.

24. Stefanidis D, Heniford BT. The formula for a successful laparoscopic skills curriculum. Arch Surg. 2009;144(1):77-82 discussion 82.

25. Singh P, Aggarwal R, Pucher PH, Darzi A. Development, organisation and implementation of a surgical skills 'Boot Camp': SIMweek. World I Surg. 2015;39(7):1649-60.

26. Pearson SA, Rolfe I, Smith T. Factors influencing prescribing: an intern's perspective. Med Educ. 2002:36(8):781-7.

27. Zibrowski EM, Weston WW, Goldszmidt MA. I don't have time': issues of fragmentation, prioritisation and motivation for education scholarship among medical faculty. Med Educ. 2008;42(9):872-8.

28. Barnsley L, Lyon PM, Ralston SJ, Hibbert EJ, Cunningham I, Gordon FC, et al. Clinical skills in junior medical officers: a comparison of self-reported confidence and observed competence. Med Educ. 2004;38(4):358-67.

\section{Publisher's Note}

Springer Nature remains neutral with regard to jurisdictional claims in published maps and institutional affiliations.

Ready to submit your research? Choose BMC and benefit from:

- fast, convenient online submission

- thorough peer review by experienced researchers in your field

- rapid publication on acceptance

- support for research data, including large and complex data types

- gold Open Access which fosters wider collaboration and increased citations

- maximum visibility for your research: over $100 \mathrm{M}$ website views per year

At $\mathrm{BMC}$, research is always in progress.

Learn more biomedcentral.com/submissions 